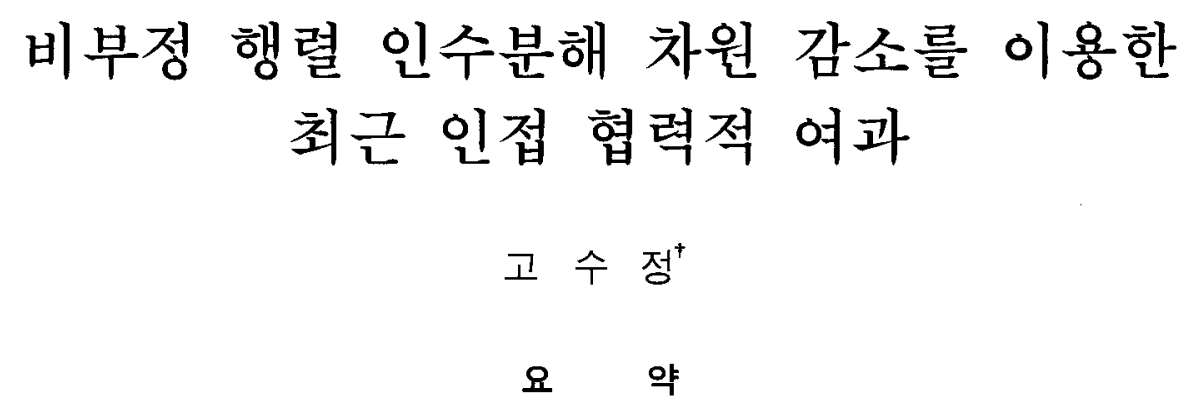

협력적 여과는 사용자 선호도를 예흑하기 위해 그 사용자의 유형을 학습하는 데 목적을 둔 기술이다. 협력적 여과 시스템이 전자상거래에서 성공적인 기술일지라도 그들은 데이터의 고차원성과 희박성이라는 문제점을 갖는다. 본 논문에서는 이와 같은 문제점을 해결하기 위하여 비부 정 행렬 인수분해(NNMF, Non-negative Matrix Factorization) 방법을 이용한 최근 인접 협력적 여과 방법을 제안한다. 행렬을 분해하기 위한 전처리로서 사용자 변동 계수롤 이용하여 사용자-아이템 행렬의 결측치를 채우고, 이를 대상으로 비부정 분해 방식을 적용하여 행렬을 인수분 해 한다. 비부정 분해 방식을 적용한 긍정 분해는 사용자들을 의미를 갖는 벡터로써 표현함으로써 사용자들을 의미 간계를 갖는 그룹으로 표현 한다. 이와 같이 벡터로 표현된 사용자들은 벡터 유사도에 의해 그들간의 유사도를 계산한다. 계산된 유사도의 정도에 의해 이웃을 결정하고, 이웃들이 평가한 아이템에 대한 홍미도를 기반으로 새로운 사용자가 평가하지 않은 아이템에 대한 결측치를 예측한다.

키워드 : 최근 인접 협력적 여과, 비부정 행렬 인수분해, 차원 감소, 사용자 변동 계수

\title{
Nearest-Neighbor Collaborative Filtering Using Dimensionality Reduction by Non-negative Matrix Factorization
}

\author{
Su-Jeong $\mathrm{Ko}^{+}$
}

\begin{abstract}
Collaborative filtering is a technology that aims at learning predictive models of user preferences. Collaborative filtering systems have succeeded in Ecommerce market but they have shortcomings of high dimensionality and sparsity. In this paper we propose the nearest neighbor collaborative filtering method using non-negative matrix factorization(NNMF). We replace the missing values in the user-item matrix by using the user variance coefficient method as preprocessing for matrix decomposition and apply non-negative factorization to the matrix. The positive decomposition method using the non-negative decomposition represents users as semantic vectors and classifies the users into groups based on semantic relations. We compute the similarity between users by using vector similarity and selects the nearest neighbors based on the similarity. We predict the missing values of items that didn't rate by a new user based on the values that the nearest neighbors rated items.
\end{abstract}

Key Words:Nearest-Neighbor Collaborative Filtering, Non-Negative Matrix Factorization, Dimensionality Reduction, User Variance Coefficient

\section{1. 서}

협력적 여과 기술은 사용자-아이템 행렬에서 가장 비슷한 훙미를 갖는 사용자들을 찾으며, 사용자들의 이웃이 형성되 었을 때 이들의 선호도를 기반으로 사용자의 선호도를 예측 한다[1,15]. 협력적 여과 기술을 이용한 추천 시스템은 이들 의 많은 장점으로 인하여 성공적인 평가를 받고 있으며 웹 에서의 추천 시스템에서 상용적으로 사용되고 있으나 그들

† 정 회 원: 인덕대학 킴퓨터소표트웨어과 교수

논문접수 : 2006 년 9월 25일, 심사완료 : 2006년 11원 7일
은 데이터 집합에서의 희박성과 고차원성이라는 단점을 갖 는다[16]. 또한, 사용자-아이템 행렬에서 모든 사용자는 모 든 아이템에 대하여 평가를 해야 할지라도 모든 사용자가 모든 아이템에 대하여 평가하는 경우는 없으므로 이로 인해 발생하는 결측치는 협력적 여과 시스템에서의 또 하나의 단 점이다[14].

데이터 집합의 희박성과 고차원성의 단점을 해결하는 방 법 중 잠재 의미 색인(Latent Semantic Indexing, LSI) 방법 을 이용하는 방법이 있다[4]. 잠재 의미 색인 방법은 고차원 의 벡터를 저차원 벡터로 변환시키는 방법 중 하나이다. 득 
이값 분해(SVD, Singular Value Decomposition)는 잠재 의 미 색인을 사용하는 대표적인 방법 중 하나이다. 특이값 분 해 방법은 고차원의 벡터를 저차원의 벡터로 분해하고, 이 를 기반으로 사용자들간의 의미 관계를 발견함으로씨 사용. 자를 군집하는 데 사용하는 방법이다[11]. 특이값 분해를 사. 용하는 방법은 사용자-아이템 행렬의 기본 잠재 속성을 찾 아내며, 대용량의 저장 공간에서도 보다 효율적으로 비슷한 사용자를 예측하여 찾음으로써 높은 성능의 추천을 제공한 다는 장점을 갖는다. 그러나 이를 이용한 분해 방법은 사용. 자-아이템 행렬의 기본 잠재 속성에 음의 값을 포함하여 사 용자들을 의미공간으로 군집시키는 것을 곤란하게 한다. 이 를 해결하기 위하여 본 논문에서는 잠재 의미 색인 방법의 하나인 비부정 행렬 인수분해(Non-negative Matrix. Factorization, NNMF)를 이용한다. 비부정 행렬 인수분해 방법은 대용량의 데이터에서 지수적인 함수관계를 발견하는 데 있어 매우 유용하게 사용되며, 사용자들을 군집하고자 할 때 사용자들간의 의미 관계를 발견할 수 있다는 장점을 갖는다[8,9,19]. 또한, 특이값 분해 방법과는 다르게 행렬 분 해에 있어서 직교 행렬을 필요로 하지 않는다는 장점도 갖 는다[8].

비부정 행렬 인수분해를 이용한 최근 인접 협력적 여과 방법은 행렬을 분해하기 위한 전처리로써 사용자-아이템 행 렬의 결측치를 채운다. 행렬의 결측치를 채우기 위해 사용 할 방법은 사용자 변동 계수를 이용한 방법이다[20]. 제안한 방법에서는 수식을 이용하여 자동적으로 사용자 변동 계수 의 임계값을 선택하고, 그 임계값에 따라 사용자 평균에서 아이템 평균으로 전환하여 사용자들의 결측치에 대한 기본 평가값을 결정한다. 이와 같은 방법으로 사용자-아이템 행 렬의 결측치를 채운 후에 그 행렬을 대상으로 비부정 분해 방식을 적용한다. 비부정 분해 방식을 적용한 긍정 분해는 사용자들을 의미를 갖는 벡터로써 표현함으로써 사용자들을 의미 관계를 갖는 그룹으로 표현한다. 이와 같이 벡터로 표. 현된 사용자들은 벡터 유사도에 의해 그들간의 유사도를 계 산한다. 계산된 유사도의 정도에 의해 이웃을 결정하고, 이 웃들이 평가한 아이템에 대한 훙미도를 기반으로 새로운 사 용자가 평가하지 않은 아이템에 대한 결측치를 예측한다.

본 논문은 2 장에서 사용자 변동 계수를 이용한 기본 평가 값 예측 방법을 이용하여 완전 행렬을 구성하는 방법을 기 술하고, 3 장에서는 비부정 행렬 분해를 사용하여 사용자-아 이템 행렬의 차원을 감소시키고, 이를 기반으로 사용자의 특징을 표현한다. 그리고 4장에서는 최근 인접 사용자 선택 방법을 기술하며, 5 장에서는 제안된 방법과 기존의 방법의 성능을 비교하여 평가한다. 마지막으로 6장에서는 결론을 기술한다.

\section{2. 완전 행렬 구성}

비부정 분해 방식을 사용자-아이템 행렬에 적용하기 위 하여 우선적으로 완전 행렬을 구성하는 전처리 작업을 한다.
이를 위하여 사용자-아이템 행렬에 있는 결측치를 기본 평 가값으로 채운다[20]. 본 논문에서 사용한 방법에서는 사용 자 변동 계수를 이용한 기본 평가값 뎨측 방법이다. 사용자 평균이나 아이템 평균 중 어느 값을 기본 평가값으로 사용 할 것인가를 결정하기 위해 MovieLens 데이터 집합.10]에서 100 명의 사용자씩을 임의로 선택하여 5 개의 모집단을 만들 었다. 이들 데이터 집합의 실제 데이터를 결측치로 가정한 후에, 이에 대한 기본 평가값으로 사용자 평균과 아이템 평 균을 각각 사용하였다. 그 결과, 2 개의 집단에서는 사용자 평균을 사용하였을 경우 결측치 오차가 낮아지는 결과를 보 였으며, 나머지 집단에서는 아이템 평균을 사용하였을 경우 결측치 오차가 낮아지는 결과를 보였다. 이와 같은 결과는 사용자들이 아이템에 대하여 평가한 경향에 따라 두 가지 값 중 하나의 값을 기본 평가값으로 결정해야 한다는 결론 을 내릴 수 있다. 변동 계수를 이용한 기본 평가값 평가의 방법에서는 사용자들이 아이템에 대하여 평가한 경향을 판단 하는 기준으로 데이터 점둘의 변동 정도를 나타내는 변동 계 수를 사용한다. 식 (1)은 변동 계수를 계산하기 위한 식이다.

$$
C V=(S / X) \times 100
$$

식 (1)에서 $C V$ 는 변동 계수를 의미하고, $S$ 는 표준 편차, 그리고 $X$ 는 사용자가 아이템에 대하여 평가한 값의 평균을 나타낸다.

각 사용자들에 대한 기본 평가값을 결정하기 위하여 사용 자 변동 계수의 임계값을 정한다. 사용자-아이템 행렬에 속 한 사용자들의 변동 계수 평균에 따라 사용자 평균에서 아 이템 평균으로 전환되는 임계값이 달라지나 사용자 변동 계 수의 분포 또한 그 임계값에 영향을 미친다. 따라서 임계값 을 결정하기 위하여 사용자 변동 계수의 분포 정도를 나타 내는 왜도(skewness of distribution)를 사용자 변동 계수 평 균의 보정값으로서 사용한다. 이러한 임계값은 사용자 변동 계수의 평균과 그 분포의 규칙성을 이용하여 자동으로 결정 한다. 본 논문에서는 사용자 변동 계수의 분포 정도를 구하 기 위하여 식 (2)의 왜도[6]를 사용하였다.

$$
\text { skewness }=\frac{n}{(n-1)(n-2)} \sum_{i=1}^{n}\left(\frac{x_{i}-\bar{x}}{s}\right)^{3}
$$

식 (2)에서 $\bar{x}$ 는 사용자 변동 계수의 평균을 나타내고, $\mathrm{s}$ 는 변동 계수의 표준 편차, $\mathrm{n}$ 은 사용자-아이템에 있는 전체 사용자의 수이다.

식 (3)은 왜도가 1 보다 클 경우 그 값에 로그값을 취한 결과를 나타냄으로써 임계값을 결정한다.

$$
\begin{aligned}
& \text { Threshold }{ }_{c v}=1-\left(\mathrm{CV}+\mathrm{C}_{-} \text {difference }\right) \\
& C_{\text {_difference }}=\log \text { skewness, }(\text { skewness }>0)
\end{aligned}
$$

식 (3)에서 Threshold $\mathrm{cv}_{\mathrm{c}}$ 는 사용자 변동 계수의 딥계값을 
나타내며, $\mathrm{CV}$ 는 사용자 변동 계수의 평균을 나타낸다. 그리 고 C_difference는 사용자 변동 계수의 보정값을 나타낸다.

반면, 왜도가 0 보다 크고 1 과 같거나 작은 범위에 속할 경우, 이에 대한 로그의 값은 음의 값이 나오거나 계산할 수 없는 경우가 발생한다. 이와 같은 음의 값은 평균 사용 자 변동 계수에 대한 보정값으로 사용할 수 없다. 따라서 이와 같은 범위의 왜도에 대해서는 새로운 함수가 정의되어 야 한두.

왜도가 0 보다 크고 1 과 같거나 작을 경우 식 (4)를 적용 하여 평균 사용자 변동 계수에 대한 보정값을 계산한다.

$$
C_{\text {differnece }}=10^{\text {skewness }-e^{0.88}}(0<\text { skewness } \leq 1)
$$

식 (3)과 식 (4)와 같이 결정한 변동 계수의 임계값을 기 준으로 사용자가 평가하지 않은 결측치를 기본 평가값으로 채운다. 이를 위하여 각 사용자의 변동 계수가 임계값보다 작다면 사용자 평균을, 아닐 경우 아이템 평균을 사용한다.

<표 1>은 기본 평가값을 채우기 위한 사용자-아이템 행

〈표 1〉사용자-아이템 행렬의 예

\begin{tabular}{|c|c|c|c|c|c|c|c|c|c|c|c|c|c|c|}
\hline & 1 & 2 & 3 & 4 & 5 & 6 & 7 & 8 & 9 & 10 & 11 & 12 & 13 & $\begin{array}{c}\text { 사용자 } \\
\text { 평균 }\end{array}$ \\
\hline ul & 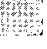 & 0.6 & 0.4 & 0.8 & 0.2 & 0.2 & 0.4 & 0.8 & 0.2 & 0.6 & 0.8 & 0.4 & 0.8 & 0.5167 \\
\hline u 2 & 0.8 & 0.4 & 0.4 & 0.8 & 0.8 & 0 & 1 & 0.6 & 0.6 & 1 & 0 & 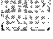 & 0.6 & 0.5833 \\
\hline u3 & 1 & 0.8 & 0.8 & 0.8 & 0.8 & Whe & W & 0.8 & 0.6 & 0.8 & 0 & 1 & 1 & 0.7636 \\
\hline U4 & 0.2 & 0 & 0.4 & 0.4 & 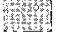 & 0 & 0.6 & 0 & 0.4 & 0 & 0.4 & 0.4 & 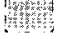 & 0.2545 \\
\hline u 5 & 0.6 & 4 & 0.4 & 0.8 & 0.4 & 0 & 0.4 & 1 & 0 & 0.8 & 0.8 & 1 & 0.4 & 0.5500 \\
\hline u6 & 0.8 & 0 & 0.2 & 1 & 0 & 0 & 0.6 & 0.4 & (4) & 1 & 1 & 0.4 & 1 & 0.5333 \\
\hline u 7 & 0.6 & 0.6 & 0.6 & 0.8 & 0 & 0.2 & 0.6 & 0.8 & 0.6 & 0.8 & 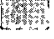 & 0.8 & 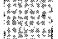 & 0.5818 \\
\hline u 8 & 1 & 0.8 & 0.8 & 0.8 & 0.2 & 0.4 & 0.8 & 0.8 & 0 & 0.8 & 1 & 11 & 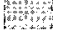 & 0.7 \\
\hline $\begin{array}{l}\text { u } 9 \\
\mathbf{u}\end{array}$ & 1 & 0.8 & 0.8 & 0 & 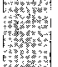 & 0.2 & 0.6 & 0 & 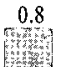 & 0.8 & 0.8 & 1 & 0.4 & 0.6 \\
\hline 10 & 0.6 & 0.6 & 1 & 0.8 & 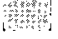 & 0 & 0.8 & 0.2 & 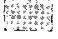 & 0.8 & 0.8 & 0.6 & 0.8 & 0.6363 \\
\hline $\begin{array}{l}\text { 평 } \\
\text { 규 }\end{array}$ & 0.73 & 0.51 & 0.58 & 0.7 & 0.34 & 0.11 & 0.64 & 0.54 & 0.4 & 0.74 & 0.62 & 0.73 & 0.71 & 0.5719 \\
\hline
\end{tabular}

〈표 2〉기본 평가값으로 채운 완전 행렬

\begin{tabular}{|c|c|c|c|c|c|c|c|c|c|c|}
\hline & 1 & 2 & 5 & 6 & 7 & 9 & 11 & 12 & 13 & $\begin{array}{l}\text { 변동 } \\
\text { 계수 }\end{array}$ \\
\hline u1 & 073 & 0.6 & 0.2 & 0.2 & 0.4 & 0.2 & 0.8 & 0.4 & 0.8 & 0.4800 \\
\hline u2 & 0.8 & 0.4 & 0.8 & 0 & 1 & 0.6 & 0 & 0733 & 0.6 & 0.5747 \\
\hline 43 & 1 & 0.8 & 0.8 & 0764 & 076 & 0.6 & 0 & 1 & 1 & 0.3670 \\
\hline U4 & 0.2 & 0 & 0,343 & 0 & 0.6 & 0.4 & 0.4 & 0.4 & 0.714 & 0.8672 \\
\hline u5 & 0.6 & 0511 & 0.4 & 0 & 0.4 & $\frac{0}{4}$ & 0.8 & 1 & 0.4 & 0.6226 \\
\hline u6 & 0.8 & 0 & 0 & 0 & 0.6 & 04 & 1 & 0.4 & 1 & 0.7887 \\
\hline u7 & 0.6 & 0.6 & 0 & 0.2 & 0.6 & 0.6 & 0622 & 0.8 & 9114 & 0.4469 \\
\hline u8 & 1 & 0.8 & 0.2 & 0.4 & 0.8 & 0 & 1 & 1 & 0.14 & 0.46391 \\
\hline u9 & 1 & 0.8 & 0034 & 0.2 & 0.6 & 0.8 & 0.8 & 1 & 0.4 & 0.6030 \\
\hline$u 10$ & 0.6 & 0.6 & 0,343 & 0 & 0.8 & 04 & 0.8 & 0.6 & 0.8 & 0.4622 \\
\hline
\end{tabular}

렬로서 10 명의 사용자가 13 개의 아이템에 대해 평가한 결과 를 나타낸다. <표 1>에서 흑색부분은 결측치를 의미한다.

<표 1>을 대상으로 식 (3)과 식 (4)를 적용하여 변동 계 수의 임계값을 계산한 후, <표 2>와 같이 사용자들의 결측 치를 기본 평가값으로 채운다.

<표 2>에서 $0.733,0.764$ 둥과 평가값은 식 (3)과 식 (4) 등을 이용한 사용자 변동 계수와 왜도를 통한 기본 평가값 예측의 결과를 나타낸다.

\section{NNMF 차원 감소를 통한 사용자의 특징 표현}

본 장에서는 2 장에서와 같이 사용자-아이템 행렬을 기본 평가값으로 채운 후 $\mathrm{NNMF}$ 를 이용하여 행렬의 차원을 감소 시키고, 이를 기반으로 사용자의 특징을 의미 속성 관계로 표현한다.

\subsection{NNMF 차원 감소}

사용자-아이템 행렬을 $\mathrm{R}$ 로 정의 하자. 행렬 $\mathrm{R}$ 을 비부정 인자로 분해하기 위하여 사용자-아이템 행렬을 정규화한다. 행렬을 정규화하는 방법은 표준화 점수 $(z-s c o r e)$ 를 이용하는 방법, 사용자가 아이템에 대하여 평가한 값으로부터 사용자 의 평균을 빼서 그 값을 저장하는 방법이 있으며, 또한 유 클리디안 길이를 이용하는 방법이 있다[14]. 평가한 값을 사 용자가 평가한 모든 값의 평균으로 빼는 방법은 표준화 점 수를 이용하는 방법보다 정확도가 높으나 0보다 작은 값이 나올 수 있기 때문에 비부정 인자로 분해하는 방법에는 부 적당하다. 따라서 본 논문에서 제안된 방법에서는 정규화를 위하여 유클리디안 길이를 사용한다.

헙력적 여과 추천에서 사용할 사용자-아이템 행렬은 $\mathrm{R}=\left\{\mathrm{r}_{\mathrm{jij}}\right\}$ 로서 표현한다. 비부정 행렬 분해는 기저 벡터(base vector)의 집합과 은닉 벡터(hidden vector)의 집합으로부터 비부정 인자(factor)를 찾아냄으로써 행렬의 차원을 감소한 다[18]. 은닉 벡터 집합의 열은 행렬 $\mathrm{R}$ 의 열과 일대일로 대 응한다. 본 논문에서는 행렬 $\mathrm{R}$ 의 전치행렬로서 $\mathrm{R}^{\mathrm{T}}$ 를 정의한 다. 비부정 분해는 $R^{T} \approx P C$ 의 근사분해이다. 행렬 $\mathrm{P}$ 는 $\mathrm{m} \_\mathrm{x} \_\mathrm{t}$ 의 크기를 갖는 기저 벡터이며, 행렬 $\mathrm{C}$ 는 $\mathrm{t} \_\mathrm{x} \_n$ 의 크 기를 갖는 은닉 벡터이다. 여기서 $\mathrm{t}$ 는 $\mathrm{n}$ 과 $\mathrm{m}$ 보다 작다. $P \geq 0$ 와 $C \geq 0$ 에 대해 $\left\|R^{T}-P C\right\|^{2}$ 의 값을 최소화한다[21]. 첫 번째 단계에서 $\mathrm{P}$ 와 $\mathrm{C}$ 는 임의의 비부정 행렬로 초기화된 다. 다음으로 $\left\|R^{T}-P C\right\|^{2}$ 의 값이 수렴할 때까지 이 과정을 반복한다. 식 (5)는 행렬 $\mathrm{P}$ 와 $\mathrm{C}$ 를 수렴시키기 위하여 순차 적으로 계산하기 위한 식이다[8].

$$
P_{i a}=P_{i a} \frac{\left(R^{T} C^{T}\right)_{i a}}{\left(P^{T} C C^{T}\right)_{i a}} \quad C_{a \mu}=C_{a \mu} \frac{\left(P^{T} R^{T}\right)_{a u}}{\left(P^{T} P C\right)_{a \mu}}
$$

식 (5)에 의해 $\mathrm{R}^{\mathrm{T}}$ 는 $\mathrm{t}$ 개의 의미 속성을 가진 $\mathrm{P}$ 와 $\mathrm{C}$ 로 분 


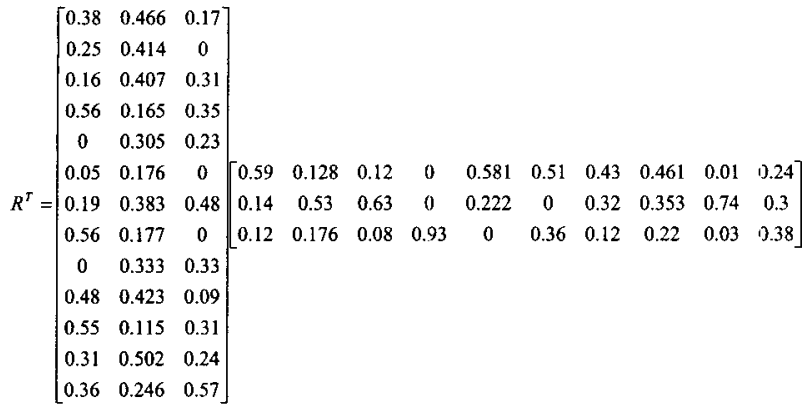

(그림 1) 행렬 RT를 $A P$ 와 $\mathrm{AC}^{\top}$ 로 분해

해된다. 분해가 된 행렬 $\mathrm{R}^{\mathrm{T}}$ 는 식 (6)과 같이 표현할 수 있다.

$$
R^{T}=A P \cdot A C^{T}=\left[A p_{1, \ldots, \ldots} A p_{a, \ldots, \ldots} A p_{t}\right]\left[A c_{l, \ldots, t} A c_{a, \ldots, \ldots} A c_{t}\right]^{T}
$$

식 (6)에서 $\mathrm{AP}$ 는 비부정 $\mathrm{m} \_\mathrm{x}$ t 차원의 행렬이며, $\mathrm{AC}$ 는 비부정 $n_{-} x_{-} t$ 행렬이다. $\mathrm{Ap}_{\mathrm{a}}$ 와 $\mathrm{Ac}_{\mathrm{a}}$ 는 각각 $\mathrm{m}$ 과 $\mathrm{n}$ 의 행렬요 소를 갖는 $\mathrm{a}$ 번째 열벡터이다. 열벡터 $\mathrm{Ap}_{\mathrm{a}}$ 는 $\left(\mathrm{ap}_{\mathrm{a} 1}, \mathrm{ap}_{2} 2, \cdots, \mathrm{ap}_{\mathrm{a}}\right.$ $\left.\mathrm{j}, \cdots, \mathrm{ap}_{\mathrm{am}}\right)$ 의 요소를 가지며, $\mathrm{Ac}_{\mathrm{a}}$ 는 $\left(\mathrm{ac}_{\mathrm{a} 1}, \mathrm{ac}_{2} 2, \cdots, \mathrm{ac}_{\mathrm{a}}, \cdots, \mathrm{ac}_{\mathrm{ar}}\right)$ 의 요소를 갖는다. 열벡터 $\mathrm{Ap}_{\mathrm{a}}$ 와 $\mathrm{Ac}_{\mathrm{a}}^{\mathrm{T}}$ 는 $\mathrm{AP}$ 와 $\mathrm{AC}^{\mathrm{T}}$ 의 $t$ 개 의 미 속성 중에서 a번째 속성에 대한 아이템과 사용자의 가중 치를 나타낸다.

<표 2>를 대상으로 비부정 분해를 설명하기 위하여 $t$ 를 3 으로 정의를 했다고 가정한다. $\mathrm{t}=3$ 인 경우, <표 $1>$ 에 나타 난 사용자-아이템 행렬의 결측치를 <표 2>와 같이 채운 후 에, 이에 대한 전치 행렬 $\mathrm{R}^{\mathrm{T}}$ 를 분해한다. 그 결과, (그림 1) 과 같이 $\mathrm{AP}$ 와 $\mathrm{AC}^{\mathrm{T}}$ 를 얻었다.

본 논문에서 제안한 방법에서는 아이템을 대상으로 하지 않고 사용자를 대상으로 그들의 의미 속성을 관계를 추출한 다. 즉, 사용자와 아이템간의 관계가 아니고, 사용자간의 유 사도를 계산하여 가장 비슷한 홍미를 갖는 이웃들을 찾는 것을 목적으로 한다. 그러나, 행렬 $\mathrm{R}^{\mathrm{T}}$ 는 $\mathrm{t}$ 개의 의미 속성을 갖는 아이템과 사용자 모두의 관계를 표현하므로 식 (6)에 서 행렬 $\mathrm{AP}$ 의 열을 정규화하여 그들의 길이를 1 로 정의함 으로써 아이템이 갖는 가중치를 제거한다. 그 결과, $\mathrm{t}$ 개의 의미 속성에 대한 아이템 가중치를 정규화를 통하여 제거함 으로써 사용자들과 $t$ 개의 의미 속성만이 고려된다. 식 (7)은 식 (6)의 행렬 $\mathrm{AP}$ 와 $\mathrm{AC}$ 를 정규화하기 위한 식이다.

$$
\begin{aligned}
& A P=\left[\frac{A p_{1}}{\left\|A p_{i}\right\|_{2}}, \cdots, \frac{A p_{a}}{\left\|A p_{a}\right\|_{2}}, \ldots, \frac{A p_{i}}{\left\|A p_{t}\right\|_{2}}\right] \\
& A C=\left[A c_{1} \cdot\left\|A p_{1}\right\|_{2}, \ldots, A c_{a} \cdot\left\|A p_{a}\right\|_{2}, \ldots, A c_{t} \cdot\left\|A p_{t}\right\|_{2}\right]
\end{aligned}
$$

$\mathrm{AC}^{\mathrm{T}}$ 는 10 명의 사용자가 3 개의 의미 속성에 대해 갖는 가 중치를 식 (7)를 사용함에 의하여 표현할 수 있다. <표 3> 은 식 (7)을 (그립 1)의 자료에 적용한 후에 얻은 결과를 보

\begin{tabular}{|c|c|c|c|c|c|c|c|c|c|c|}
\hline & $u 1$ & $\mathrm{u} 2$ & u3 & $u 4$ & U5 & u6 & U7 & u8 & 49 & $u^{\neq} 0$ \\
\hline $\begin{array}{l}\text { 의미 } \\
\text { 속성 } 1\end{array}$ & 0.752 & 0.165 & 0.148 & 0 & 0.747 & 0.651 & 0.548 & 0.593 & 0.006 & 0.303 \\
\hline $\begin{array}{l}\text { 의미 } \\
\text { 속성2 }\end{array}$ & 0.168 & 0.649 & 0.771 & 0.002 & 0.272 & 0.000 & 0.394 & 0.43 & 0.90 & 0.369 \\
\hline $\begin{array}{l}\text { 의미 } \\
\text { 속성3 }\end{array}$ & 0.131 & 0.186 & 0.082 & 0.98 & 0 & 0.381 & 0.125 & 0.023 & 0.029 & 0.398 \\
\hline
\end{tabular}
인다.
〈표 3〉 정규화된 배열 $\mathrm{AC}^{\top}-$ 사용자의 의미 속성 가중치

\section{2 사용자의 특징 표현}

3.1 절에서 아이템-사용자 행렬 $\mathrm{R}^{\mathrm{T}}$ 에서의 사용자와 아이템 의 특징을 $\mathrm{t}$ 개의 의미 속성에 대한 $\mathrm{t}$ 차원 가중추 벡터로써 표현하였다. 이를 기반으로, 사용자간의 유사도는 각각의 가 중치 벡터의 유사도를 계산함으로써 구할 수 윳다. [19]의 연구에서는 문서의 특징을 $t$ 개의 의미 속성과의 관계로 표 현할 수 있도록 비부정 행렬 분해를 이용한 문서 분류 방법 을 제안하였다. 비부정 행렬 분해를 이용한 문서 분류 방법 에서는 문서들을 행렬로 표현하고, 이를 비부정-행렬 인수 분해를 사용하여 비부정 인자로 분해하였다. 이와 같이 행 렬을 기저 벡터와 은넉 벡터 기반으로 분해하고, 벡터들로 부터 문서들을 몇 몇의 가중치를 갖는 의미 속섣들의 집합 으로 표현한다. 이 연구에서는 문서를 의미 속솓들 중에서 가장 큰 가중치를 갖는 의미 속성의 그룹으로 문서를 분류 하는 방법을 제안하였다. 비부정 행렬 분해를 0 용한 문서 분류 방법은 문서 분류의 정확도와 속도면에서 효율적이나 문서를 가장 큰 값의 가중치를 갖는 하나의 속싱을 기반으 로만 분류을 한다는 단점을 갖는다. 예를 들어, 둔:서를 사용 자로 가정하였을 경우, <표 $3>$ 에 있는 사용자 $\mathrm{u} 10$ 은 3 개의 의미 속성에 대해 $0.303,0.369,0.398$ 의 값을 갖는다. 따라서 이 방법에서 제안된 방법에 의하면 이 사용자는 의미 속성3 에 가장 큰 가중치를 갖기 때문에 의미 속성 3 으 그릅으로 분류된다. 반면, 이 사용자는 의미 속성 1 이나 의미 속성 2 에 대하여도 거의 유사한 가중치를 갖고 있으나 다릇 의미 속 성이 갖는 가중치 값은 고려되지 않는다. 또한, 그룹의 수가 전체 의미 속성의 수와 같다는 또 다른 단점이 딨다. 본 논 문에서는 사용자를 $t$ 개의 의미 속성에 대해 정규화된 가중 치를 갖는 벡터로서 사용자를 표현한다. 사용자 $\mathrm{u}_{\mathrm{i}}$ 를 $\mathrm{t}$ 차원 으로 식 (8)과 같이 표현한다.

$$
u_{i}=\left(a c_{1 i} \cdot \frac{\left\|A p_{1}\right\|_{2}}{\left\|A c_{t}\right\|_{2}}, \ldots a c_{a i} \cdot \frac{\left\|A p_{a}\right\|_{2}}{\left\|A c_{a}\right\|_{2}}, \ldots, a c_{t i} \cdot \frac{\|\left. A p_{t}\right|_{2}}{\left\|A c_{t}\right\|_{2}}\right)
$$

식 (8)과 같이 표현한 사용자를 함수로 나타내기 위하여 사용자를 함수로써 표현하면 식 (9)와 같다. 식 (9)는 $\mathrm{u}_{i}$ 를 의미 속성 $\left(\mathrm{s}_{1}, \mathrm{~S}_{2}, \cdots, \mathrm{s}_{\mathrm{a}}, \cdots, \mathrm{S}_{\mathrm{t}}\right)$ 에 대한 함수식으로서 포현한 결과이다.

$$
u_{i}=F_{i}\left(s_{l}, s_{2}, \ldots, s_{t}\right)
$$

식 (9)에서 $\mathrm{F}_{\mathrm{i}}$ 는 사용자 $\mathrm{u}_{\mathrm{i}}$ 가 각 의미 속성에 대해 갖는 
가중치로, 식 (10)과 같이 나타낸다.

$$
F_{i}=\left(f_{1 i}, f_{2 i}, \ldots, f_{a i}, \ldots, f_{t i}\right)
$$

식 (10)에서 $\mathrm{f}_{\mathrm{ai}}$ 는 사용자 $\mathrm{u}_{\mathrm{i}}$ 가 $\mathrm{a}$ 번째의 의미 속성에 대해 갖는 가중치이다.

<표 3>의 사용자를 식 (8)를 이용하여 정규화한 후 식 (9)의 형태로 표현했을 때 다음과 같이 3차원 벡터로 표현 할 수 있다.

$$
\begin{aligned}
& u 1=(0.4918,0.1079,0.1135) \\
& u 2=(0.108,0.418,0.161) \\
& u 3=(0.1,0.5,0.07)
\end{aligned}
$$$$
\mathrm{u} 10=(0.198,0.237,0.344)
$$

\section{4. 최근 인접 사용자 선택}

3 장에서와 같이 사용자를 $t$ 개의 의미 속성에 대한 가중치 벡터로 표현한 후, 이를 이용하여 새로운 사용자에 대한 최 근 이웃을 구할 수 있다. 사용자에 대한 최근 인접 사용자 를 선택하기 위하여 벡터 공간 모델을 이용한다. 벡터 공간 모델은 정보 검색 분야에서 광범위하게 사용되고 있는 방법 이다 $[12,13]$. 상당히 많은 검색 엔진들이 웹문서의 순위를 나 열하기 위해 유사도를 사용한다. 이와 같은 모델은 문서와 질어어를 벡터에 의해 표현함으로써 하나의 공간으로 사상 시킨다. 내적곱과 같은 유사도 함수는 문서와 질의어 사이 의 유사도를 계산하는 데 사용되어 왔다.

식 (11)은 식 (9)와 같이 정의된 사용자 $\mathrm{u}_{i}$ 와 새로운 사용 자 $u_{k}$ 가 $t$ 개의 의미 속성에 대한 가중치를 기반으로 이들간 의 벡터 유사도를 구하는 식이다[22].

$$
S\left(u_{i}, u_{k}\right)=\frac{\sum_{a=1}^{t} f_{a i} \cdot f_{a k}}{\sqrt{\sum_{a=1}^{t} f_{a i}^{2}} \cdot \sqrt{\sum_{a=1}^{t} f_{a k}^{2}}}
$$

(그림 2)는 <표 $3>$ 의 사용자들을 벡터로 표현하여 가시 화시킨 결과를 나타낸다.

식 (11)을 이용하여 기존에 있는 사용자와 새로운 사용자 의 유사도를 계산하여 새로운 사용자에 대한 최근 인접의 사용자들을 찾는다. <표 4>는 <표 3>의 사용자들을 대상으 로 식 (11)을 적용하여 유사도를 계산한 결과이다.

사용자 $\mathrm{u}_{\mathrm{k}}$ 에게 문서를 추천하기 위해서는 식 (11)의

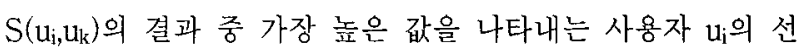
호도를 기반으로 아이템의 예상 선호도를 계산하고, 이 선 호도가 일정 임계값 이상일 경우 추천한다. <표 1>에서와

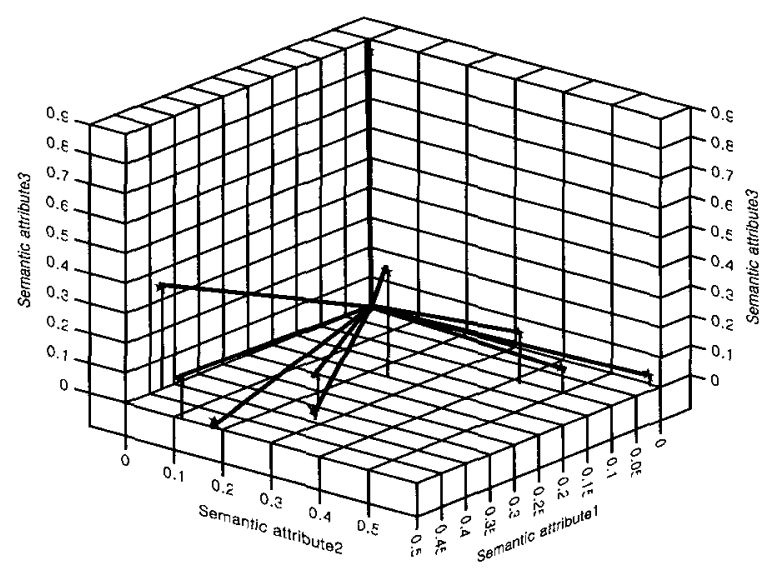

(그림 2) 시각화를 이용한 최근 인접 여과

〈표 4〉벡터 유사도를 이용한 사용자간의 유사도

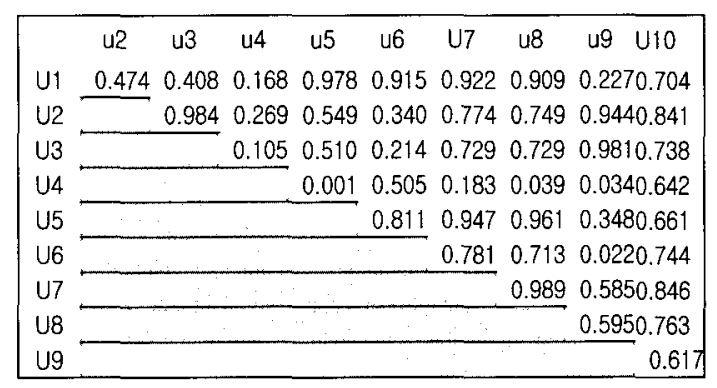

같이 사용자의 선호도는 0.2 간격으로 $0 \sim 1$ 사이의 값을 나타 내므로, 그 중간값인 0.5 로 임계값을 설정한다. 사용자 $u_{k}$ 의 특정 아이템 $\mathrm{j}$ 에 대한 선호도 $\mathrm{p}_{\mathrm{kj}}$ 는 식 (12)를 이용한다[1].

$$
p_{k j}=\overline{r_{k}}+\frac{\sum_{i=1}^{n} S\left(u_{i}, u_{k}\right)\left(r_{i j}-\overline{r_{i}}\right)}{\sum_{i=1}^{n} S\left(u_{i}, u_{k}\right)}
$$

$\mathrm{p}_{\mathrm{kj}}$ 는 새로운 사용자 $\mathrm{u}_{\mathrm{k}}$ 가 문서 $\mathrm{j}$ 에 대해 예측한 선호도 값 이고, $\overline{r_{k}}$ 는 새로운 사용자 $\mathrm{u}_{\mathrm{k}}$ 의 선호도 평균이다. $\mathrm{S}\left(\mathrm{u}_{\mathrm{i}}, \mathrm{u}_{\mathrm{k}}\right)$ 는 새로운 사용자 $\mathrm{u}_{\mathrm{k}}$ 와 사용자 $\mathrm{u}_{\mathrm{i}}$ 의 유사도 가중치이고, $\mathrm{n}$ 은 새 로운 사용자 $\mathrm{u}_{\mathrm{k}}$ 와 다른 사용자들 간의 유사도가 0 이 아닌 사용자 수이다.

<표 3>에 있는 사용자들 중 $\mathrm{u} 10$ 이 새로운 사용자라고 가정하고 새로운 아이템을 추천하고자 식 (12)에 대입할 경 우의 결과는 식 (13)과 같다.

$$
p_{10,5}=3.673 \quad p_{10,9}=0.4539
$$

\section{5. 성능 평가}

본 논문에서 제안한 비부정 행렬 인수분해를 이용한 최근 인접 협력적 여과 방법의 성능을 평가하기 위하여 평균 절 
대 오차(MAE)[5,7]를 사용하였으며, 기존의 방법들과 메개 변수에 대한 사용의 민감성을 고려하면서 그 성능을 비표하 였다. 성능 평가 결과의 분석은 대응일치 $\mathrm{t}$-검증(paired t-test)[3,14]과 $95 \%$ 의 신뢰도 수준에서 본페로니 즐차 (Bonferroni procedure for multiple comparison statistics!의 에이노바(ANOVA) 분석[2,17]을 사용하였다. MAE는 사용 자-아이템 행렬에서 실제 평가값과 예측값 사이의 차이를 기반으로 그 정확도를 측정한다. $\mathrm{MAE}$ 는 추천의 정확도를 측정하기 위해 가장 통상적으로 사용하는 방법이며, 가장 쉬운 방법이기도 하다. $\mathrm{n}$ 개의 결측치를 갖는 데이터 집합에 서 실제 평가 값이 $\mathrm{a}_{\mathrm{i}}$ 이고, 예측된 값이 $\mathrm{p}_{\mathrm{i}}$ 인 경우, $\mathrm{MAE}$ 는 식 (14)에 의해 계산된다.

$$
M A E=\frac{\sum_{i=1}^{n} a_{i}-p_{i}}{n}
$$

비부정 행렬 인수분해를 이용한 최근 인접 협력적 여과 방법의 성능을 평가하기 위해 GroupLens Research Center 의 MovieLens 평가 데이터를 사용하였다[10]. MovieLens 데이터 집합은 6040 의 사용자들이 3960 의 영화에 대해, 총 1000000 의 평가를 하였다. 기존의 협력적 여과 연구는 다양 한 사용자 집합을 대상으로 실험을 하였다. 예를 들어, [16] 의 연구에서는 943 명을 대상으로, [3]는 1400 명을 대상으로, [1]에서는 5000명을 대상으로 실험을 하였다. 본 논문에서는 1000 명의 사용자를 데이터 집합으로부터 무작위로 선택하였 으며, 그 사용자들은 0 에서 1 까지 0.2 의 간격으로 30 개의 영 화보다 더 많은 영화에 대하여 평가하였다.

비부정 행렬 인수분해를 이용한 최근 인접 협력적 여과 방법의 성능을 평가하기 위해 10 개의 데이터 집합으로 나눈 다. 10 개의 데이터 집합은 dataset 1 , dataset $2, \cdots$, dataset 10 으 로 표기하였다. 사용자의 평가 정보는 각 데이터 집합마다 다르며, 그 분포는 비부정 행렬 인수분해를 이용한 최근 인 접 협력적 여과 방법의 정확도에 영향을 미친다. 따라서, 그 데이터 집합을 10 개로 나눔에 의해 데이터의 분포 정보를 고려하였다. 각 데이터 집합은 훈련 데이터 집합과 테스트 데이터 집합으로 구분하였다. 훈련 데이터 집합은 사용자아이템 행렬로부터의 실제 데이터 집합이고, 테스트 데이터 집합은 비부정 행렬 인수분해를 이용한 최근 인접 협력적 여과 방법의 정확도를 평가하기 위하여 사용되었다.

비부정 행렬. 인수분해를 이용한 최근 인접 협력적 여과 방법의 성능(NMF_C)은 SVD를 이용하여 결측치롤 예측하 는 방법(SVD_C)[11], 비부정 행렬 인수분해를 이용하여 사 용자를 속성으로 분류한 뒤에 이를 이용하여 결측치를 예측 하는 방법(NMF_SC)[19] 피어슨 상관 계수를 이용하여 결측 치를 예측하는 방법(Pearson_C)[15]과 비교하였다.

<표 5>는 10 개의 데이터 집합에서 비부정 행렬 인수분해 를 이용한 최근 인접 협력적 여과 방법의 성능을 나타낸다. 즉, $\mathrm{SVD}$ 를 이용하여 결측치를 예측하는 방법(NMF_C), 키 부정 행렬 인수분해를 이용하여 사용자를 속성으로 분류한
〈표 5〉 NMF_C, Pearson_C, SVD_C, 그리고 NMF_SC의 성능 비고

\begin{tabular}{|c|r|r|r|r|}
\hline & Pearson_C & \multicolumn{1}{c|}{ SVD_C } & NMF_SC & NMF_C \\
\hline \hline dataset1 & 0.315364 & 0.275913 & 0.221 & 0.168135 \\
\hline dataset2 & 0.262964 & 0.206156 & 0.221714 & 0.163556 \\
\hline dataset3 & 0.210897 & 0.173893 & 0.178602 & 0.11381 \\
\hline dataset4 & 0.283124 & 0.253333 & 0.2514 & 0.206924 \\
\hline dataset5 & 0.218834 & 0.194455 & 0.172339 & 0.11823 \\
\hline dataset6 & 0.224639 & 0.214168 & 0.17427 & 0.14041 \\
\hline dataset7 & 0.216429 & 0.226957 & 0.211731 & 0.13479 \\
\hline dataset8 & 0.217727 & 0.158382 & 0.157589 & 0.1067 \\
\hline dataset9 & 0.179929 & 0.150461 & 0.143023 & 0.098848 \\
\hline dataset10 & 0.233889 & 0.223961 & 0.17769 & 0.1463 \\
\hline 평균 & 0.23637943 & 0.207767 & 0.1909357 & 0.13977029 \\
\hline
\end{tabular}

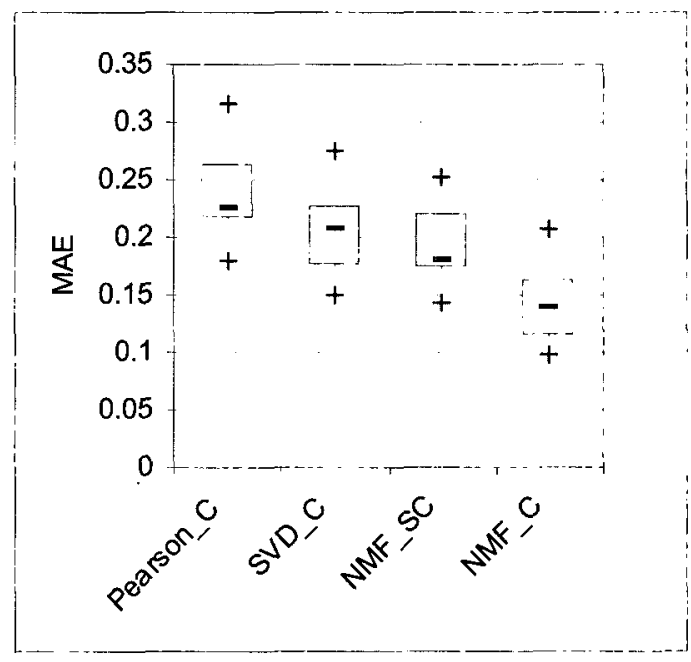

(그림 3) 비부정 행렬 인수분해를 이용한 최근 인접 협 력적 여과 방법의 성능 비교

뒤에 이를 이용하여 결측치를 예측하는 방법(NMF_SC), 피 어슨 상관 계수를 이용하여 결측치를 예측하는 방법 (Pearson_C)과 비교하였을 경우 성능의 결과를 보인다.

(그림 3)은 NMF_C, Pearson_C, SVD_C, 그리고 $\mathrm{NMF}$ _SC의 성능을 보이고 있으며, <표 5>를 기반으로 하 였다.

(그림 3)에서 <표 5>의 각 열은 하나의 상자에 해당한다. 각 상자에서 상자 위 't' 기호는 최대값이며, 상자 아레 '+' 기호는 최소값에 해당한다. 평균은'"-' 기호에 의해 표현되 었다.

<표 5>와 (그림 3)에서 NMF_C를 이용한 방법을 사용하 였을 경우 나머지 다른 방법들보다 보다 성능이 우수함을 보인다. NMF_SC를 이용한 방법은 하나의 의미 속성만으로 사용자를 표현함으로 인하여 그 정확도가 저하됨을 볼 수 있다. SVD_C를 이용한 방법은 음의 값을 갖는 잠채 속성으 로 인한 오차로 인하여 정확도가 낮음을 보인다. 마지막으 로, Pearson_C의 방법은 행렬의 희박성 문제로 인하여 정확 도가 가장 낮음을 볼 수 있다.

<표 6>은 대응일치 $\mathrm{t}$-검증과 $95 \%$ 의 신뢰도 수준에서의 
〈표 6〉 비부정 행렬 인수분해를 이용한 최근 인접 협력적 여과 방법의 성능 비교의 신뢰도 수준

\begin{tabular}{|cccccc|}
\hline & NMF_C & NMF_SC & SVD_C & Pearson_C & (Mean) \\
NMF_C & ---- & 0.04132 & 0.04132 & 0.04132 & 0.1398 \\
NMF_SC & yes & ---- & 0.04132 & 0.04132 & 0.1909 \\
SVD_C & yes & no & $-\cdots$ & 0.04132 & 0.2078 \\
Pearson_C & yes & yes & no & $-\ldots .-$ & 0.2364 \\
\hline
\end{tabular}

다중 비교의 본페로니 절차의 에이노바 분석을 사용한 결과 의 통계적인 신뢰성을 나타낸다. <표 6>의 오른쪽 상단부는 대응일치 t-검증을 이용한 각각의 방법들간의 신뢰도를 의 미하며, 그룹들간 평균에서의 차이를 나타낸다. 왼쪽 하단부 는 에이노바 분석을 통해 각 방법들간에 신뢰성이 있는가의 유무를 의미한다.

<표 6>에서 NMF_C와 NMF_SC, SVD_C, 그리고 Pearson_C의 신뢰도 유무를 나타낼 때, NMF_C는 모든 방 법과의 성능 차이에서 신뢰도가 있음을 볼 수 있다. 반면, NMF_SC는 SVD_C와는 큰 차이가 없으며, Pearson_C와는 성능 차이에 있어 신뢰도가 있음을 알 수 있다. SVD_C는 Pearson_C와 성능 차이에 있어 신뢰도가 없음을 나타낸다. 결론적으로, NMF_C의 방법은 NMF_SC, SVD_C, Pearson_C와의 성능 비교에 있어서 성능이 높음을 증명할 수 있다.

\section{6. 결 론}

본 논문에서는 협력적 여과 시스템에서의 희박성을 해결 하기 위하여 비부정 행렬 인수분해를 이용한 차원 감소를 통한 최근 인접 협력적 여과 방법을 기술하였다. 사용자-아 이템 행렬을 대상으로 비부정 행렬 인수분해를 적용하기 위 해서는 그 행렬의 기본 평가값 예측이 행해져야 한다. 이를 위하여 사용자-아이템 행렬을 대상으로 사용자 변동 계수를 이용한 기본 평가값 평가 알고리즘을 적용하여 결측치를 채 웠다. 사용자 변동 계수를 이용하여 기본 평가값을 결측치 를 채우는 방법은 모든 결측치를 동일한 값으로 평가하는 기존의 방법과는 다르게 사용자의 특성을 고려하였다. 즉, 사용자 변동 계수와 평가 분포의 왜도를 이용하므로 기존의 기본 평가값 평가 방법들보다 높은 정확도를 보였다. 비부 정 행렬 인수분해를 이용한 최근 인접 헙력적 여과 방법은 고차원의 사용자-아이템 행렬의 차원을 감소시키며, 행렬의 잠재 의미 속성 분석을 통하여 비슷한 사용자들의 그룹을 찾을 수 있었다. 성능분석 결과, SVD와 같이 차원을 감소시 키면서 동시에 사용자롤 군집시키는 방법과의 성능을 비교 했을 때, 그 성능이 높음을 보였으며, 일반적인 협력적 여과 알고리즘과 비교하였을 경우 상당히 성능이 높음을 보였다. 또한, 비부정 행렬 인수분해를 이용하여 행렬의 차원을 축 소한 뒤 무조건 하나의 의미 속성으로 사용자를 분류하는 방법보다도 높은 성능을 보였다.

\section{참 고 문 헌}

[1] John. S. Breese, D. Heckerman, and C. Kadie, "Empirical Analysis of Predictive Algorithms for Collaborative Filtering," Proceedings of the Conference on Uncertainty in Artificial Intelligence, Madison, WI, 1998.

[2] Giuseppe Carenini, Rita Sharma, "Exploring More Realistic Evaluation Measures for Collaborative Filtering," Proceeding of AAAI 2004, 2004.

[3] Sonny Han Seng Chee, Jiawei Han, and Ke Wang, "RecTree: An Efficient Collaborative Filtering Method," Proceedings of the Third International Conference on Data Warehousing and Knowledge Discovery, September, 2001.

[4] S. Deerwester, S. T. Dumais, G. W. Furnas, T. K. Landauer, and R. Harshman, "Indexing by latent semantic analysis," Journal of the American Society for Information Science, Vol. 41, No. 6, 1990.

[5] J. Delgado and N. Ishii, "Formal Models for Learning of User Preferences, a Preliminary Report," In Proceedings of International Joint Conference on Artificial Intelligence (IJCAI-99), 1999.

[6] L. Grossi, G. Gozzi, and P. Ganugi, "Distribution Analysis of Items and Ratios in Companies?Accounts using a new iterative procedure," Proceedings of compstat2002, 2002.

[7] Jonathan L. Herlocker, Joseph A. Konstan, Loren G. Terveen, and John T. Riedl, "Evaluating collaborative filtering recommender systems," ACM Transactions on Information Systems (TOIS) archive, Vol. 22, No. 1, 2004.

[8] Lee, D. and Seung, H., "Algorithms for non-negative matrix factorization," Advances in Neural Information Processing Systems, pp. 556-562, 2001.

[9] Liu, W. and Yi, J., "Existing and New algorithms for nonnegative matrix factorization," Tech. rep., Department of Computer Sciences, University of Texas at Austin, 2003.

[10] MovieLens collaborative filtering data set, Http://www. cs.umn.edu/Research/GroupLens/index.html, GROUPLENS RESEARCH PROJECT, 2000.

[11] M. H. Pryor, "The effects of singular value decomposition on collaborative filtering," Technical Report PCS-TR98338, Compute Science Department, Dartmouth College, 1998.

[12] V. Rijsbergen and C. Joost, Information Retrieval, Butterworths, London-second edition, 1979.

[13] G. Salton and M. J. McGill, Introduction to Modern Information Retrieval, McGraw-Hill, 1983.

[14] B. Sarwar, G. Karypis, J. Konstan, and J. Riedl, "Application of Dimensionality Reduction in Recommender System A Case Study," Proceddings of ACM WebKDD, 2000. 
[15] B. Sarwar, J. Konstan, Al Borchers, J. Herlocker, H. Miller, and J. Riedl, "Using Filtering' Agents to Improve Prediction Quality in the GroupLens Research Collaborative Filtering System," Proceedings of the 1998 Conference on Computer Supported Cooperative Work, 1998.

[16] B. Sarwar, G. Karypis, J. Konstan, and J. Riedl, "Analysis of recommendation algorithms for $\mathrm{e}^{-\mathrm{com}}$ merce," Proceedings of the 2nd ACM conference on Electronic commerce, 2000.

[17] Rita Sharma and David Poole, "Symmetric Collaborative Filtering Using the Noisy Sensor Model," Proceedings of the 17 th Conference. in Uncertainty in Artificial Intelligence, 2001.

[18] Simon Shepherd, Non-Negative Matrix Factorization, http://www.simonshepherd.supanet.com/nnmf.htm, 2004.

[19] Wei Xu , Xin Liu , and Yihong Gong, "Document clustering based on non-negative matrix factorization," Proceedings of the 26th annual international ACM SIGIR conference on Research and development in information retrieval, July 28-August 01, 2003.

[20] 고수정, “협력적 여과 시스템에서 사용자 변동 계수를 이동 한 기본 평가값 예측”, 정보과학회논문지, 제 32 권, 11 월, 2005.

[21] 김윤희, "Non-negative Matrix Factorization을 이용한 텍 스트 문서 및 마이크로어례이 데이터 분석”, 서울대학고 학사 학위논문, 2003.

[22] 김혜재, 손기락, " $\mathrm{K}$-최근접 이웃 추천 엔진에서의 벡터 유 사도 사용에 대한 실험적 분석", 정보과학회 춘계 학술발 표논문집(B), 제 28 권, 제 1 호, 2001.

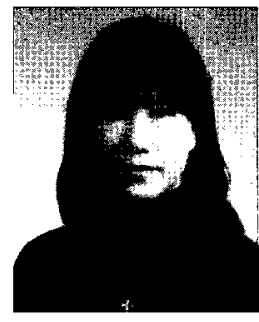

\section{고 수 정}

email : sjko@induk.ac.kr

1990 년 인하대학교. 전자계산학과 졸업(학사)

1997년 인하대학교.

$$
\text { 전자계산교육전공(석사) }
$$

2002년 인하대학교. 전자계산공학.가(박사)

2003년 2004년 University of Illinois at Urbana-Champaign Post Doc.

2004년 -2005년 Colorado State University Research Szientist 2005년 현재 인덕대학 컴퓨터소프트웨어과 교수 관심분야: 데이터마이닝, 정보검색, 기계학습 등 